\title{
Color and the boundary of entoptic space
}

GORDON STANLEY

INDIANA UNIVERSITY

After viewing either red or green entoptic after-images, $S$ s made adjustments of the distance of a projection screen so that the apparent size of the then projected after-image equalled that of the entoptic after-image. The effect of varying the chromatic color of the inducing stimulus had no significant effect on these adjustments. The after-image method was compared to Katz' direct estimation procedure and was considered to be superior.

In an earlier study (Stanley, 1966a) the author reported that estimates of an entoptic after-image showed small variability despite the fact that distance estimates were highly variable. The size estimates were not a simple reflection of habitual response tendencies, nor did they bear a simple relationship to the actual dimensions of the inducing stimulus. To account for the consistent size estimates it was proposed that although the subjective impression is of boundless space, with eyes closed the visual system acts as if the eyes are fixated at a finite rather than infinite distance. In a subsequent experiment (Stanley, 1966b), Ss viewed an after-image entoptically and then opened their eyes and adjusted the distance of a projection screen so that the apparent size of the now projected after-image equalled that of the previously seen after-image. This procedure yielded an estimate of $8.44( \pm 3.04)$ in. for the "boundary" of the entoptic space.

Katz (1935) obtained direct estimates of the localization of "visual grey" (his term for what is here referred to as entoptic space). First, Ss were trained to judge the localization of changes in the brightness of the entoptic field induced by briefly shining a light on the closed eyelids. Subsequently he obtained direct estimates of the relatively darker visual field itself. There were considerable individual differences and estimates ranged from $10-40 \mathrm{~cm}$. It should be noted that the boundary of entoptic space obtained by means of after-images (Stanley, 1966b) falls approximately in the center of this range. However, Katz (1935, p. 65) asserted that after-images are always localized at a distance distinctly different from that of the surround with chromatic after-images generally being localized nearer. He also claimed that there are differences in localization as a function of differences in chromatic color, red and yellow being seen as nearer than the other colors.

The present study was designed to investigate the effects of chromatic color on the estimates of the boundary of entoptic space obtained using the method of after-images.

\section{Subjects}

Ss were 43 male students from an introductory psychology class who were screened on the Bausch and Lomb Orthorater and had an equivalent of 20/20 vision in their right eye.

\section{Apparatus}

The after-image inducing stimulus was located at 20 in. in front of $S$ and consisted of a circle of 1-in. diameter lighted by a Sylvania BEH 15-hr. $150 \mathrm{~W}$ $120 \mathrm{~V}$ projection lamp. Depending on experimental conditions, Kodak Wratten filter No. 26 (red) or No. 58 (green) was placed in front of the lamp. The projection screen was viewed by $S$ through a $1-$ in. aperture mounted at the end of a 39-in. rule and consisted of an 8-in. square of white plastic mounted on a slide fitted to the rule. It was possible for the screen to be adjusted from 0 to 39 in. The room was feebly illuminated, the luminance of the projection screen as measured by a Macbeth Illuminometer being 0.03 apparent $\mathrm{ft} . \mathrm{-c}$.

Procedure

Ss were tested individually and read the instructions previously reported (Stanley, 1966b). Essentially they stressed that the $S$ was to get a clear impression of the size of the entoptic after-image, then to project the after-image on to the projection screen and adjust until its size equalled that of the entoptic after-image. After the adjustment $S$ was asked to estimate the diameter of the latter. For $22 \mathrm{Ss}$ the inducer was red, the remaining 21 Ss received green induction.

\section{Results}

Table 1 lists the means and standard deviations for distance adjustments and diameter estimates for both experimental groups.

Although the difference between the mean adjustments of distance is in the predicted direction it is trivial in comparison to variance, and a $t$ test for independent samples yielded a ratio of 0.37 which is not significant $(p=0.7)$. Similarly, a $t$ test between diameter estimates failed to reach significance $(t=$ $1.20,0.2>p>.3)$.

The present results are essentially the same as

Table 1. Mean and standard deviations of distance adjustments and diameter estimates for red and green inducers.

\begin{tabular}{|c|c|c|c|c|}
\hline \multirow[t]{2}{*}{ Inducer } & \multicolumn{2}{|c|}{$\operatorname{Red}(N=22)$} & \multicolumn{2}{|c|}{ Green $(N=21)$} \\
\hline & $x$ & $\sigma$ & $x$ & $o$ \\
\hline Distance & 7.94 & 3.36 & 8.24 & 1.37 \\
\hline Diameter & 0.34 & 0.19 & 0.28 & 0.12 \\
\hline
\end{tabular}


previously obtained (Stanley, 1966b) and suggest that the after-image procedure is a relatively stable method of estimating the "boundary" of entoptic space. In contrast to Katz (1935), the present author has been unsuccessful at obtaining consistent direct estimates of the boundary of entoptic space (Stanley, 1966a). It is true that the former used trained Ss, but it seems preferable to use after-image projection which does not require extensive subject-training.

References

Katz, D. The world of colour. London: Kegan, Paul, 1935. Stanley, G. The apparent size of entoptic after-images. Psychon. Sci., 1966a, 4, 289-290.

Stanley, G. The boundary of entoptic space. Psychon. Sci., 1966b, $5,45-46$. 